\title{
Nicholas Sims-Williams. Corpus of Christian Sogdian texts with Syriac parallel texts Supplementary to A Dictionary: Christian Sogdian, Syriac and English
}

Christelle Jullien

\section{(2) OpenEdition \\ Journals}

Édition électronique

URL : https://journals.openedition.org/abstractairanica/54162

DOI : 10.4000/abstractairanica.54162

ISSN : 1961-960X

Éditeur :

CNRS (UMR 7528 Mondes iraniens et indiens), Éditions de l'IFRI

Référence électronique

Christelle Jullien, « Nicholas Sims-Williams. Corpus of Christian Sogdian texts with Syriac parallel texts Supplementary to A Dictionary: Christian Sogdian, Syriac and English », Abstracta Iranica [En ligne], Volume 42-43 | 2021, document 27, mis en ligne le 30 décembre 2021, consulté le 03 janvier 2023. URL: http://journals.openedition.org/abstractairanica/54162 ; DOI : https://doi.org/10.4000/ abstractairanica.54162

Ce document a été généré automatiquement le 3 janvier 2023.

Tous droits réservés 


\title{
Nicholas Sims-Williams. Corpus of Christian Sogdian texts with Syriac parallel texts Supplementary to A Dictionary: Christian Sogdian, Syriac and English
}

\author{
Christelle Jullien
}

\section{RÉFÉRENCE}

Nicholas Sims-Williams. Corpus of Christian Sogdian texts with Syriac parallel texts Supplementary to A Dictionary: Christian Sogdian, Syriac and English. 2nd edition, revised and completed. Wiesbaden: Reichert Verlag, 2020.

1 Cette base de données exceptionnelle est consacrée aux textes chrétiens sogdiens et permet de rendre accessible le matériau aujourd'hui connu. Ce vaste corpus mis en ligne, et sur lequel est basée l'édition du Dictionnaire anglais / chrétien sogdien / syriaque, est consultable gratuitement. Depuis la première édition de ce Dictionnaire en 2016, salué comme un outil majeur (voir le compte rendu dans Abstracta Iranica, $\mathrm{n}^{\circ}$ 37-38-39/2014-2016), plusieurs éditions de textes en sogdien étaient parues (notamment Barbati en 2016, Reck en 2018, et dans les BTT de 2017 et 2019), nécessitant sa remise à jour complète. Nombre de textes en sogdien sont des traductions d'ouvrages en syriaque, et l'un des intérêts, et non des moindres, de cette littérature est de conserver trace de plusieurs œuvres aujourd'hui disparues. Alliée au Dictionnaire et notamment à l'index complet très pratique en fin de volume, cette BDD est un instrument de travail de première importance.

2 Elle se présente sous la forme d'un fichier Excel (consultable sur le site de l'éditeur: fichier xls à télécharger). L'A. a pris en compte toute la littérature chrétienne 
sogdienne existante : la base comprend ainsi les termes repérés dans l'intégralité des manuscrits connus, ceux en écriture sogdienne et ceux en écriture syriaque (E1-E57, et l'inscription MIK III/365), avec les textes parallèles syriaques identifiés, et parfois des renvois aux parallèles en d'autres langues lorsqu'il s'agit de termes plus proches du sogdien. Sur les 27020 lignes que compte le fichier, les 1.25807 à la fin sont dévolues aux deux Psautiers et à d'autres textes chrétiens en sogdien.

La colonne A donne le $n^{\circ}$ de la ligne

4 La colonne $\mathrm{B}$ renvoie à la nomenclature précise du manuscrit d'où le mot est tiré.

5 La colonne D comprend les mots en sogdien ordonnés suivant les manuscrits.

6 La colonne E comprend les mots en syriaque suivant l'ordre du sogdien.

7 Ces deux colonnes (D et $\mathrm{E}$ ) intègrent les révisions (corrections textuelles) du Dictionnaire ( $2^{e}$ éd.) de Nicholas Sims-Williams, Iranian manuscripts in Syriac script in the Berlin Turfan collection, (Verzeichnis der orientalischen Handschriften in Deutschland, Band XVIII/4: Mitteliranische Handschriften, Teil 4), Stuttgart: Steiner, 2012, (online).

Les La colonnes $\mathrm{C}$ et $\mathrm{F}$ contiennent respectivement les textes sogdiens et syriaques en version simplifiée.

9 L'A. souligne les possibles incohérences de présentation, très légères, dans la présentation de ce matériau. La recherche peut s'effectuer par mot ou par séquences de caractères. Il est possible de convertir le fichier Excel au format ".htm", ce qui permet la recherche de mots entiers, ou de l'ouvrir dans Access pour des croisements plus complexes. Comme le souligne l'A. dans son préliminaire mis en ligne sur la page de présentation du Dictionnaire du site de Reichert Verlag, aucun autre texte chrétien sogdien substantiel n'a été trouvé depuis la troisième expédition effectuée à Turfan en 1907 ; aussi la BDD apparaît-elle comme une référence pérenne pour la consultation du matériau réuni. Nul doute qu'elle rendra d'inestimables services aux iranistes, syriacisants et philologues travaillant sur l'Orient chrétien. Voir également le compte rendu de la deuxième édition de "A Dictionary: Christian Sogdian, Syriac and English" dans ce même numéro d'Abstracta Iranica.

\section{AUTEURS}

CHRISTELLE JULLIEN

CNRS, CeRMI, Paris 